\title{
A dinâmica não linear da educação a distância: um olhar a partir da complexidade
}

\author{
The non-linear dynamics of distance education: a look \\ from the complexity
}

\section{La dinámica no linear de la educación a distancia: una mirada a partir de la complejidad}

\section{Celso José Martinazzo, Juliana Giacomelli Griebeler*}

\section{Resumo}

Neste texto temos como objetivo identificar e analisar possíveis pontos de convergência entre o processo de Educação a Distância e o princípio da não linearidade da teoria da complexidade. Busca-se compreender a Educação a Distância (EaD) a partir de um olhar do pensamento complexo, sobretudo tendo o princípio da não linearidade como uma das categorias de análise. O princípio da complexidade permite tecer considerações muito férteis sobre o processo de educação e do ensino a distância. Os cursos de $\mathrm{EaD}$ são organizados e ministrados com base em Tecnologias de Informação e Comunicação (TICs) que, embora se caracterizem por movimentos lineares, permitem ações e criações complexas 
não lineares. O texto foi elaborado com base na metodologia de pesquisa descritiva e interpretativa, com apoio em referências bibliográficas e eletrônicas, tendo como fonte os autores que abordam e analisam essa temática.

Palavras-chave: Complexidade. Educação a Distância. Princípio da não linearidade.

\begin{abstract}
In this text we aim to identify and analyze possible points of convergence between the process of Distance Education and the nonlinearity principle of the complexity theory. It seeks to understand Distance Education from a complex thinking perspective, especially having the nonlinearity principle as one of the categories of analysis. The principle of the complexity allows us to make very fertile considerations about the process of distance learning and education. The Distance Education courses are organized and taught based on the Information and Communication Technologies (ICTS) which, although characterized by linear movements, allow for nonlinear complex actions and creations. The text was elaborated based on the descriptive and interpretive research methodology, with support in bibliographical and electronic references, having as source the authors that approach and analyze this theme.
\end{abstract}

Keywords: Complexity. Distance Education. Principle of non-linearity.

\title{
Resumen
}

En este texto tenemos como objetivo identificar y analizar posibles puntos de convergencia entre el proceso de Educación a Distancia y el principio de la no linealidad de la teoría de la complejidad. Se busca comprender la Educación a Distancia (EaD) a partir de una mirada del pensamiento complejo, sobre todo teniendo el principio de la no linealidad como una de las categorías de análisis. El principio de la complejidad permite hacer consideraciones muy fértiles sobre el proceso de educación y de enseñanza a distancia. Los cursos de EaD se organizan y son ministrados con base en Tecnologías de Información y Comunicación 
(TICS) que, aunque se caracterizan por movimientos lineales, permiten acciones y creaciones complejas no lineales. El texto fue elaborado con base en la metodología de investigación descriptiva e interpretativa, con apoyo en referencias bibliográficas y electrónicas, teniendo como fuente los autores que abordan y analizan esa temática.

Palabras clave: Complejidad. Educación a distancia. Principio de la no linealidad.

\section{Introdução}

\section{Considerações iniciais sobre a complexidade e a educação a distância}

Pensar a Educação a Distância (EaD) na perspectiva do pensamento complexo de Edgar Morin e de outros estudiosos da teoria da complexidade nos remete à análise e compreensão de alguns princípios cognitivos que regem e orientam o pensar complexo. Neste texto, temos como objetivo analisar e compreender a dinâmica da Educação a Distância à luz dos pressupostos do paradigma da complexidade, sobretudo a partir do princípio da não linearidade que é inerente aos fatos e fenômenos complexos - entre eles o processo de Educação a Distância.

Muitos estudiosos, ao longo do século 20, já antecipavam que o século 21 seria o século da expansão e consolidação da complexidade, antevendo, de certa forma, a crise e a revolução dos fundamentos do conhecimento científico e a explosão de novas descobertas na área da informática e cibernética. O despertar da complexidade, no entanto, já havia tido algumas emergências ao longo da história da filosofia e da ciência desde os seus primórdios.

As formas tradicionais de pensar, não raras vezes, operaram no sentido de simplificar o que, por natureza, é complexo. Pela via do conhecimento reduziram o complexo em algo simples. Por outro lado, a ciência moderna, com base no método científico, promoveu e continua a promover enormes avanços tecnológicos com base na fragmentação, na hiper-especialização do conhecimento e na redução da complexidade. Por esta razão, apesar de representar um 
avanço em relação a outras formas tradicionais de conhecimento, esse modelo é responsável por produzir as bases epistemológicas de uma forma de conhecer que Morin (2000c) denomina de paradigma da simplificação.

Se por um lado o modelo de conhecimento simplificador é sumamente importante para o avanço da ciência, sobretudo porque ele se traduz na eficiência de resultados e produtos, por outro lado, no entanto, ele contém limitações e restrições quando se trata de fornecer explicações sobre determinados contextos e realidades. Em consequência, esse paradigma tem sido objeto de críticas por conta de sua insuficiência epistemológica ao explicar fenômenos complexos. Por esta razão, concordamos com o pensamento de Folloni (2016, p. 87): “Tradicionalmente, a utilidade e a possibilidade da redução enquanto recurso metodológico para a explicação científica são bastante aceitas, mas esse consenso tem sofrido abalos".

As revoluções científicas que ocorreram a partir de meados de século 20 começam a apontar para uma ontologia complexa e, por essa razão, tornaram necessários outros enfoques epistemológicos para sua compreensão. Com base nessa constatação, Morin (2006) vai insistir em uma "reparadigmatização" ou em uma virada paradigmática capaz de promover o que ele denomina de uma verdadeira metamorfose do pensamento para civilizar as ideias (MORIN, 2015). Cientistas de diferentes áreas do conhecimento começaram a se dar conta da necessidade de buscar outras formas de racionalidade que tenham um maior poder de explicar e compreender a realidade. A racionalidade complexa aposta em um olhar aberto, multiocular e multidimensional, tendo como ponto de partida alguns princípios epistemológicos mais pertinentes do que aqueles consagrados pela forma clássica de pensar ${ }^{1}$.

1 É necessário explicitar que o pensamento complexo não despreza e nem descarta os demais modelos de conhecimento. Ao contrário, o pensamento complexo compõe-se de movimentos circulares, complementares e recursivos com os demais tipos de conhecimento. Este entendimento pode ser constatado na obra de Morin (2013a) quando ele faz uma reconstrução da gênese e evolução do pensamento complexo. Em um debate sobre a epistemologia da complexidade Morin (2002, p. 131) escreve: "O problema da complexidade e da simplicidade pode ser visto como uma união e como um combate", ou seja, tais saberes são antagônicos e, ao mesmo tempo, intercomplementares. 
No contexto do panorama atual de alta complexidade, de globalização e de tecnologias avançadas, Edgar Morin (2000b), pensador francês contemporâneo, defende o que ele denomina de conhecimento pertinente, com a capacidade de perceber, compreender e contemplar o contexto, o global, o multidimensional e o complexo. Isso implica distinguir e conjugar os conhecimentos, sem, contudo, promover a sua desintegração, ou seja, procurando religar os saberes. O pensamento complexo, portanto, tem a pretensão de abarcar e garantir a multidimensionalidade dos enfoques sobre a realidade, pela via da transdisciplinaridade, sem, contudo, deixar de contemplar o local, o específico e o particular. Em palavras mais convincentes: "Na verdade, trata-se de ultrapassar o paradigma da ciência e da lógica clássicas, sem rejeitá-las, mas integrando-as em um paradigma da complexidade" (MORIN, 2013a, p. 151).

A complexidade é, nas palavras de Morin e Le Moigne (2000), ainda um conceito incongruente, mais desafio que solução e receita. O desafio maior consiste em reunir o que é analisado em separado e em como compreender e enfrentar as incertezas, ambiguidades e emergências. A complexidade apresenta-se como mais uma tentativa de dialogar com o real que resiste a qualquer conceito e não como uma receita a ser aplicada. E, por esta razão, segundo Folloni (2016, p. 101), isso se traduz em um paradoxo epistêmico: "para conhecer é preciso reduzir, mas reduzir inviabiliza o conhecer. Daí a complexidade ser compreendida, sobretudo, como um desafio". O fato é que, mesmo tendo a percepção de que a tessitura do real é algo complexo, ainda estamos tentando captar e compreender essa realidade de maneira simplificada e com o olhar da lógica formal, produzindo um verdadeiro descompasso entre o real ontológico e o olhar epistemológico.

Refletir sobre uma temática com as características de um sistema complexo, como é o processo de Educação a Distância, pressupõe e implica que tenhamos de recorrer a algumas categorias e princípios que são próprios da teoria da complexidade, como é o caso da não linearidade. 
A Educação a Distância ${ }^{2}$, no Brasil, está completando duas décadas desde que foi regulamentada, em 10 de fevereiro de 1998, pelo Decreto-Lei $\mathrm{n}^{\circ}$ 2.494, do Ministério da Educação (MEC). Este Decreto foi exarado para regulamentar o artigo 80 da Lei de Diretrizes e Bases da Educação Nacional — Lei no 9.394/96, de 20 de dezembro de 1996. Desde então esta modalidade de ensino vem se constituindo de forma cada vez mais vigorosa no cenário educacional. As políticas educacionais têm contribuído para o incremento da oferta, tendo em vista que o Brasil precisa ampliar o percentual de pessoas com um grau maior de escolaridade. Em 25 de maio de 2017 o Governo Federal publicou o Decreto $n^{\circ}$ 9.057, normatizado pela Portaria do MEC no 11, de 26 de junho de 2017, com o objetivo de flexibilizar ainda mais a oferta da EaD, possibilitando a criação de cursos de $\mathrm{EaD}$ pelas próprias instituições, sem necessidade de autorização prévia do MEC. Além disso, as instituições de ensino superior poderão criar cursos na forma de EaD sem que tenham de ofertar vagas presenciais: para isso basta que tenham um conceito Muito Bom ou Excelente nas avaliações do MEC.

\section{Complexidade e o princípio da não linearidade}

O grande desafio da teoria da complexidade consiste em descobrir e formular princípios cognitivos compatíveis e pertinentes que possam nos aproximar da compreensão da complexidade do real. É um pressuposto óbvio que para a compreensão de algo que se apresenta como complexo precisamos dispor de uma epistemologia complexa ${ }^{3}$. Com base na constatação de que o real é governado por uma lógica complexa

2 A definição oficial de educação a distância consta no artigo 1ㅇ do Decreto no 5.622/05: "Caracteriza-se a educação a distância como modalidade educacional na qual a mediação didático-pedagógica nos processos de ensino e aprendizagem ocorre com a utilização de meios e tecnologias de informação e comunicação, com estudantes e professores desenvolvendo atividades educativas em lugares ou tempos diversos".

3 Sob esse enfoque a ontologia tem precedência sobre a epistemologia. Afirma Demo (2002, p. 42) que "[...] para colocar-se o intento de captar a realidade, antes é mister ter alguma noção de como seria a realidade". 
é necessário estabelecer algumas vias que permitam compreender essa realidade complexa. Pedro Demo expressa essa necessidade de uma forma muito clara: "Se não sei bem o que seria o real ontologicamente falando, muito menos sei bem como seria possível reconstruí-lo da maneira mais inteligente, epistemologicamente falando" (2002, p. 185). É com base na constatação desse fosso existente entre a ontologia e a epistemologia que Morin aponta para a necessidade e urgência de se fazer uma reforma do pensamento e esta seria um pressuposto para todas as demais reformas4. Com essa compreensão, em obra conjunta, Morin e Le Moigne, no início deste século, escrevem que "Pensar a complexidade - esse é o maior desafio do pensamento contemporâneo, que necessita de uma reforma no nosso modo de pensar" (2000, p. 199).

A ciência clássica que se consolida entre os séculos 17 e 19, inspirada, sobretudo, nas leis de Galileu e Newton, constitui-se com base na pressuposição de uma realidade estática, determinista e ordenada e, para isso, ela formulou leis mecânicas, objetivas e lineares que permitissem o acesso e a sua compreensão. Por alguns séculos a ciência explicou a grande narrativa da evolução do universo como se fosse uma máquina ou um relógio mecânico com seus movimentos cíclicos, previsíveis e ordenados. Com isso, ela teve a pretensão de subentender uma espécie de ordem permanente que rege as leis da natureza. Elimina toda e qualquer possibilidade de desordem, acidente, recursividade e incerteza. Essa matriz de pensamento foi transposta e imposta como um modelo para todas as demais ciências.

Inicialmente é preciso compreender os aspectos gerais que envolvem o princípio da não linearidade no contexto da complexidade. Trata-se, essencialmente, do reconhecimento acerca da não proporcionalidade entre ação e reação e das possibilidades raras que coexistem com as certezas.

4 A questão da reforma no nosso modo de pensar é um tema recorrente em várias das obras mais recentes de Morin, pois, segundo ele, a reforma é um pressuposto para um pensar complexo e prérequisito para as mudanças. $O$ pensamento complexo pode se constituir em embasamento teórico para uma reforma do pensamento ou das mentalidades, que é imprescindível para uma reforma do conhecimento e uma reforma da educação. As reformas são interdependentes entre si e, portanto, alimentam e se realimentam umas das outras em um movimento recursivo (MORIN, 2000a).

Rev. Diálogo Educ., Curitiba, v. 18, n. 57, p. 478-493, abr./jun. 2018 
O comportamento não linear, característico dos sistemas complexos, é aquele cuja resposta a um determinado estímulo não é, necessariamente, proporcional à intensidade e à extensão desse estímulo. Não há uma ordem linear entre causa e efeito e vice-versa, ou mesmo entre início, meio e fim. O efeito feedback quebra a linearidade de tal forma que a causa age sobre o efeito e o efeito age sobre a causa, tornando-se causador ao retroagir sobre a causa. Assim, pelo fenômeno da recursividade, os elementos funcionam ora como causa e ora como efeito. É próprio de um pensamento fragmentado e mutilado operar com base na "causalidade linear, que ignora os circuitos retroativos" (MORIN, 2013b, p. 184).

Nos modelos complexos, não é possível reconstruir o sistema como um todo por meio da soma de suas partes. Os sistemas complexos possuem estrutura não linear em virtude de os seus componentes e o ambiente no qual estão inseridos estarem interligados por processos de feedbacks recursivos, fazendo com que, ao longo do seu funcionamento, pequenas perturbações sejam ampliadas, quebrando o vínculo entre entrada e a saída subsequente (VIEIRA; GONÇALVES; MARTINS, 2015). Pelo olhar complexo descobre-se que os sistemas se regulam e organizam por uma lógica cujo percurso não está definido e delimitado. Os sistemas têm características incertas, instáveis e, de certa forma, imprevisíveis, posto que eles dependem de múltiplas variáveis. Morin (2000c) argumenta que toda e qualquer organização depende do diálogo e interação entre ordem e desordem. As emergências são fruto da combinação de elementos de equilíbrio e desequilíbrio. A evolução é composta por rupturas e crises, sendo, ao mesmo tempo, não linear e complexa. A ordem, portanto, coexiste com a desordem, ambas se equilibrando e conferindo uma nova dinâmica (VIEIRA; GONÇALVES; MARTINS, 2015). A dificuldade reside em compreender esta dinâmica multidimensional da realidade.

Se considerarmos a história da evolução biológica e social à luz dos princípios da teoria da complexidade, é isso que vamos constatar: uma evolução feita de emergências/aparecimentos e desaparecimentos, de criações e destruições, de crescimento e catástrofes, de avanços e recuos, de forma absolutamente não linear. As criações são fruto do equilíbrio e desequilíbrio, 
ou, na formulação de Morin (2000c), a evolução ocorre como um produto da integração da organização desencadeada no interior da ordem-desordem. Com o surgimento das pesquisas sobre os sistemas descobre-se a dinâmica complexa dos sistemas não lineares e que eles operam nos limites da ordem e/com desordem, produzindo emergências novas. Em decorrência do equilíbrio que se desestabiliza surge a incerteza do futuro e o controle nem sempre é viável, embora seja possível administrar o complexo. Por esta razão, ainda no início de suas pesquisas, Morin (2006, p. 104) afirma que "O mérito da complexidade é o de denunciar a metafísica da ordem".

Entre as grandes contribuições da teoria da complexidade está o mérito de demonstrar que a realidade é um todo organizado e constituído por diferentes elementos que se inter-relacionam e onde tudo está tecido junto, sendo impossível compreender a(s) parte(s) separadas do seu todo e vice-versa (MORIN, 2006). Os sistemas são autoeco-organizados e, portanto, não lineares dado que suscetíveis à influência de causas internas e externas. Os sistemas complexos e adaptativos caracterizam-se, pois, pela interatividade de seus elementos e pela imprevisibilidade do seu futuro, ou seja, pela não linearidade.

A partir dessas noções-chave da teoria da complexidade podemos fazer uma leitura e estabelecer algumas aproximações entre essa teoria com a estrutura e o funcionamento dos processos de $\mathrm{EaD}$.

\section{A dinâmica não linear das novas tecnologias e da educação a distância}

Definir a EaD como um sistema complexo é reconhecer que ela se organiza com base numa dinâmica não linear, a exemplo de outros fenômenos considerados complexos. Isso não significa afirmar que os sistemas formais de ensino presencial não sejam complexos, embora, muitas vezes, os processos de ensino e aprendizagem sejam organizados como se fossem realidades estáticas, previsíveis e ordenadas.

Pode-se definir a Educação a Distância como uma estratégia de ensino-aprendizagem que não requer a relação presencial de professor e 
alunos em recintos determinados e utiliza nova abordagem metodológica e tecnológica para a aprendizagem, em que o aluno assume um papel de autodidata. É uma modalidade de ensino/aprendizagem mediada por tecnologias que permitem ao professor e ao aluno interagirem a partir de ambientes físicos diferentes. Isso implica, portanto, novos papéis para os alunos e professores, bem como outras atitudes e enfoques metodológicos (SCHWARTZMAN; BATISTA; ALVES, 2009).

Na educação presencial, de forma predominante, os procedimentos metodológicos do processo de ensino/aprendizagem são ainda adotados com ênfase na transmissão linear de conhecimento, numa relação pedagógica que parte do professor para o aluno, enquanto que na $\mathrm{EaD}$ a aprendizagem é um processo que resulta de procedimentos predominantemente não lineares. Segundo Demo (2002, p. 124), "A escola reprodutiva considera conhecimento processo linear. Por isso, aposta em sua simples transmissão". A escola é tendencialmente reprodutiva, com procedimentos lineares do tipo impositivo e instrucionista e "o instrucionismo trata a aprendizagem como fenômeno linear: de cima para baixo, de fora para dentro, em contexto autoritário da obediência weberiana" (2002, p. 134). Por outro lado "A pedagogia interativa opta pela influência indireta sobre o educando, para que seja viável aprender a resistir à influência direta” (p. 177). A interatividade acontece pela mediação de recursos tecnológicos. Além de mudar a forma de interação, o processo de $\mathrm{EaD}$ exige do aluno uma maior autonomia em relação ao tempo e ao espaço para aprender.

As tecnologias avançadas de hoje permitem garantir a informação e a comunicação com base na organização e inovação de novos espaços, ambientes e tempos. Em EaD elas têm a função de mediar o processo de ensino e de aprendizagem, de permitir a interação entre professor e aluno e não de apenas veicular as informações e orientações, como na era em que foram utilizados o rádio e a própria televisão para esse fim. Não linearidade tem a ver, portanto, com a maneira como o receptor, o espectador ou, no caso, o aluno se organizam para participar e interagir. $\mathrm{Na}$ verdade, em processos de Educação a Distância, estão presentes os dois modelos: o linear e o não linear. Eles coexistem. A diferença está em 
que nos modelos tradicionais a forma de comunicação era exclusivamente linear e, com a Educação a Distância, o fluxo não linear é preponderante, pois se utiliza de ferramentas que permitem a interação, como as comunidades virtuais, os blogs, o Whatsapp e outros.

Demo (2002) aponta para várias características dos sistemas complexos. Segundo este autor, eles são dinâmicos, não lineares, reconstrutivos, irreversíveis, intensos e apresentam ambiguidade e ambivalência. Ao analisar a não linearidade como uma das características de um sistema complexo, esclarece que não há como fugir da necessária e imprescindível dimensão linear das tecnologias porque lhe faz parte:

[...] não cabe excluir o linear da realidade, porque também lhe faz parte. Nossas tecnologias são demonstração potente do tratamento linear efetivo - artefatos tecnológicos, também os eletrônicos, são criaturas rígidas, e nem por isso menos úteis e sofisticados. Não nos interessaria inventar avião não linear, pois ninguém estaria disposto a voar nele, já que lhe faltaria a confiabilidade dos fenômenos estáveis e estritamente recorrentes (2002, p. 15).

A EaD é organizada por seres vivos, dinâmicos e com capacidade de criação e, embora esses seres se utilizem de equipamentos replicativos lineares, não significa que a $\mathrm{EaD}$ possa ser classificada como um processo linear. Sua não linearidade deriva da criação e da relação de sujeitos dinâmicos, numa conexão de interação e ação do tipo autonomia-dependência. Para explicar tal posicionamento Demo (2002, p. 19) escreve que nas novas tecnologias a atividade criativa permanece nas mãos e cérebros do usuário humano e que "[...] a interferência humana é complexa não linear, porque interpretativa semântica, enquanto o modo de interferir precisa submeter-se à lógica binária do sistema”. E, muito embora os equipamentos eletrônicos nos estágios atuais alcancem alto grau de sofisticação, eles não podem ser considerados complexos: "Podem atingir sofisticações impressionantes, como é o caso do computador atual, mas prevalece neles o sentido de equipamento linear e por isso tanto mais confiável" (2002, p. 23). O autor acrescenta ainda: "É próprio de nossa expectativa linear que o computador seja 
máquina reversível, refazendo todos os dias os mesmos processamentos recorrentes, com absoluta confiabilidade" (2002, p. 23).

As instituições credenciadas que oferecem esta modalidade de ensino têm procurado aperfeiçoar os processos interativos de informação e comunicação entre professores/tutores e os alunos. Tentam evitar que o processo seja um mero repasse linear de informações e de conteúdos curriculares e que a processualidade torne-se cada vez mais produto de diálogo e de entendimentos. Esse canal permanente visa, sobretudo, esclarecer dúvidas sobre conteúdos, mas, também, ouvir sugestões e opiniões. A não linearidade do processo consiste em evitar o tipo hierárquico de relação professor x alunos em prol de uma mediação baseada no diálogo como um sistema de duas vias, ou seja, do tipo interativo, aberto e compartilhado.

A autonomia tem a ver com a autoprodução e a auto-organização do aluno. Ao organizar seus horários e espaços para leitura, estudo e aprendizagem, o aluno reforça a dimensão de autonomia. Sob o viés da organização linear de aprendizagem há a tendência a reforçar a dimensão da heteronomia, ou seja, o aluno organiza-se a partir da figura do professor. Para Fortin (2007, p. 108), “Organização e complexidade são termos inseparáveis um do outro". A recursividade que se estabelece entre professor $\mathrm{x}$ aluno na EaD é de uma forma mais equilibrada no sentido de autonomia $\mathrm{x}$ dependência. Se no ensino presencial a tendência é de uma relação preponderantemente direta e hierárquica do professor para o aluno, na EaD a relação é mais equilibrada no sentido de autonomia vs dependência ou autonomia $\mathrm{x}$ heteronomia.

A EaD proporciona que o aluno crie hábitos próprios para estudar e realizar suas tarefas. Sua presença na instituição de ensino a que se vincula ocorre apenas para a realização de provas e, quando necessário, para fazer pesquisa ou para outras atividades de seu interesse. Nessa modalidade de ensino o aluno tem acesso aos conteúdos de cada disciplina do seu curso por meio de mídias como televisão, vídeo, CD-ROM, telefone celular, iPod, notebook, Whatsapp e outros. Por todas essas características é que se pode concluir que a $\mathrm{EaD}$, embora opere com equipamentos que funcionam com 
base em operações lineares, é enriquecida com novas ferramentas que permitem uma processualidade dinâmica nova e não linear.

\section{Considerações finais}

Temos consciência de que a complexidade não pode ser vista como uma receita a ser aplicada em todas as situações. Morin nos alerta que "a idéia fundamental da complexidade não é a de que a essência do mundo seja complexa e não simples. É que esta essência seja inconcebível” (2006, p. 104). O real é sempre algo velado, por natureza, e por mais que tentemos decifrá-lo sempre restarão pontos obscuros. As ciências, sejam elas aplicadas ou reflexivas, mediante a inteligência humana, aventuramse em busca de novas descobertas e verdades. Sem dúvida, a descoberta da complexidade do real trouxe consigo uma contribuição fundamental, que é a necessidade da compreensão da "dinâmica não linear do conhecimento" (DEMO, 2002). Suas noções-chave, com certeza, nos permitem uma leitura mais aproximada da estrutura e funcionamento dos processos de Educação a Distância.

Na Educação a Distância, o aluno tem autonomia para programar e gerir seu tempo disponível para o aprendizado. Por apresentar uma dinâmica sedutora e inovadora, que se efetiva apoiada em ferramentas que permitem interação, é que a Educação a Distância tem se tornado uma modalidade de ensino em grande crescimento por parte das ofertas de cursos pelas instituições de ensino e que atrai cada vez mais alunos. De fato, as tecnologias de informação e comunicação são ferramentas que possibilitam uma renovação epistemológica, metodológica e, portanto, curricular. São oferecidos cursos de Graduação, Pós-Graduação e, até mesmo, cursos técnicos e profissionalizantes para o Ensino Médio.

É necessário, entretanto, atentar para estas novas configurações de ensino, na medida em que elas não devem ser meras reprodutoras do conhecimento, agindo como instrumentos de produção de novos saberes. Nesse sentido, foge-se à linearidade do óbvio, construindo-se novos 
saberes a partir de perspectivas não lineares, ou seja, não presumíveis, em que ações e reações produzem resultados fora do padrão, do esperado. Assim, a Educação a Distância permite novas configurações tanto no que se refere ao processo de ensino-aprendizagem, quanto à construção de conhecimentos, atendendo, desta forma, às novas demandas sociais.

O surgimento e a operacionalização do processo da Educação a Distância ocorrem e se viabilizam a partir de processos não lineares, uma vez que a evolução tecnológica foi se desenvolvendo de uma forma não programada e com as características de um sistema complexo. A evolução exponencial do uso das tecnologias permitiu a elaboração de novos paradigmas sociais, tecnológicos, digitais e educacionais que demonstram a convergência da complexidade com a Educação a Distância, a partir de um olhar não convencional e em virtude de sua não linearidade.

\section{Referências}

BRASIL. Decreto n ${ }^{\circ}$ 5.622/05. Regulamenta o art. 80 da Lei no 9.394, de 20 de dezembro de 1996, que estabelece as diretrizes e bases da educação nacional. Disponível em: <http://www.planalto.gov.br/ccivil_03/_Ato2004-2006/2005/ Decreto/D5622.htm>. Acesso em: 4 jul. 2017.

BRASIL. Decreto-Lei $n^{\circ}$ 2.494/98. Regulamenta o Art. 80 da LDB (Lei $n^{\circ}$ 9.394/96). Disponível em: <http://portal.mec.gov.br/seed/arquivos/pdf/tvescola/leis/D2494.pdf >. Acesso em: 1 jul. 2017.

BRASIL. Decreto ${ }^{\circ}$ 9.057/17. Regulamenta o art. 80 da Lei $n^{\circ}$ 9.394, de 20 de dezembro de 1996, que estabelece as diretrizes e bases da educação nacional. Disponível em: <http://www.planalto.gov.br/ccivil_03/_ato2015-2018/2017/ decreto/D9057.htm>. Acesso em: 1 jul. 2017. 
BRASIL. Ministério da Educação e Cultura. Portaria no 11/2017. Estabelece normas para o credenciamento de instituições e a oferta de cursos superiores a distância, em conformidade com o Decreto $\mathrm{n}^{\circ}$ 9.057, de 25 de maio de 2017. Blog Educação a Distância, 21 jun. 2017. Disponível em: <http://ok-ead. blogspot.com.br/2017/06/mec-portaria-normativa-n-11-de-20062017.html〉. Acesso em: 1 jul. 2017.

DEMO, P. Complexidade e aprendizagem: a dinâmica não linear do conhecimento. São Paulo: Atlas, 2002.

FOLLONI, A. Introdução à teoria da complexidade. Curitiba: Juruá, 2016.

FORTIN, R. Compreender a complexidade. Introdução a O Método de Edgar Morin. Lisboa: Instituto Piaget, 2007.

MORIN, E. A cabeça bem-feita: repensar a reforma, reformar o pensamento. 2. ed. Rio de Janeiro: Bertrand Brasil, 2000a.

MORIN, E. Os sete saberes necessários à educação do futuro. São Paulo: Cortez; Brasília, DF: Unesco, 2000b.

MORIN, E. Ciência com consciência. 4. ed. Rio de Janeiro: Bertrand Brasil, 2000c.

MORIN, E. Introdução ao pensamento complexo. Porto Alegre: Sulina, 2006.

MORIN, E. O problema epistemológico da complexidade. 3. ed. Lisboa: Publicações Europa-América, 2002.

MORIN, E. Meus filósofos. Porto Alegre: Sulina, 2013a.

MORIN, E. A via para o futuro da humanidade. Rio de Janeiro: Bertrand Brasil, 2013b.

MORIN, E. Ensinar a viver: manifesto para mudar a educação. Porto Alegre: Sulina, 2015.

MORIN, E.; LE MOIGNE, J.-L. A inteligência da complexidade. São Paulo: Peirópolis, 2000. 
SCHWARTZMAN, U. P.; BATISTA, K. T.; ALVES, E. D. Os saberes (des)complicados para educação a distância em saúde. Revista Comunicação em Ciências da Saúde, Brasília, v. 20, n. 3, p. 265-270, 2009.

VIEIRA, E. J.; GONÇALVES, C. A.; MARTINS, H. C. Teoria da complexidade sob a perspectiva da ambiência. Revista Eletrônica Sistemas \& Gestão, Niterói, v. 10, n. 1, p. 70-81, 2015.

Recebido: 21/11/2017

Received: 11/21/2017

Recibido: 21/11/2017

Aprovado: 11/05/2018 Approved: 05/11/2018 Aprobado: 11/05/2018 